\title{
Long-term patient and allograft outcomes of renal transplant recipients undergoing cardiac surgery
}

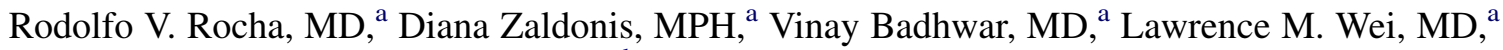 \\ Jay K. Bhama, MD, ${ }^{a}$ Ron Shapiro, MD, ${ }^{\text {b }}$ and Christian A. Bermudez, MD $^{\mathrm{a}}$
}

\begin{abstract}
Objectives: Cardiovascular complications are a major cause of morbidity and mortality among renal transplant recipients. This study assessed perioperative risk factors for mortality and long-term outcomes in renal transplant recipients who underwent cardiac surgery.
\end{abstract}

\begin{abstract}
Methods: From 1999 to 2010, 92 renal transplant recipients with a functioning allograft underwent cardiac surgery at our institution. Cardiac procedures included coronary artery bypass grafting ( 43 patients, $46 \%$ ), isolated valve surgery (17 patients, 18\%), combined coronary artery bypass grafting and valve surgery (18 patients, $19 \%)$, and aortic procedures (7 patients, $7 \%$ ).
\end{abstract}

\begin{abstract}
Results: Transient renal failure requiring dialysis occurred in 20 of 92 patients $(21 \%)$, with 3 not recovering renal function and returning to a permanent dialysis regimen while in the hospital. After cardiac surgery 30-day, 1-year, 5-year, and 8-year survival rates were $89 \%, 72 \%, 47 \%$, and $30 \%$, respectively. Freedom from dialysis was $90 \%$ after 1 year, $66 \%$ after 5 years, and $49 \%$ after 8 years. Risk factors for 30 -day mortality were age $>65$ years, left ventricle ejection fraction $<35 \%$, and a combined cardiac procedure. Pulmonary hypertension and diabetes were risk factors for death from a cardiac cause after discharge. Diabetes, dyslipidemia, preoperative use of an intra-aortic balloon pump, postoperative creatinine $>2 \mathrm{mg} / \mathrm{dL}$, and transient renal failure requiring dialysis were associated with a permanent dialysis requirement after cardiac surgery.

Conclusions: Cardiac surgery in patients receiving renal transplant who have functioning allograft has acceptable outcomes. If combined procedures are required, patients should be carefully considered. Transient postoperative renal impairment, even if resolved at discharge, increases the risk for allograft failure during long-term follow-up. (J Thorac Cardiovasc Surg 2014;147:270-5)
\end{abstract}

There are an increasing number of patients with prior kidney transplantation who require cardiac surgery. Risk factors leading to end-stage renal disease, such as diabetes and hypertension, predispose kidney transplant recipients to cardiovascular complications. In addition, the immunosuppressant regimen required after transplant is associated with deterioration of native coronary disease. ${ }^{1}$ Survival of renal transplant recipients who undergo cardiac surgery has improved, with perioperative mortality ranging from $1.4 \%$ to $9 \%$ in recent reports, as a result of careful patient selection, adequate immunosuppressive therapy, and better postoperative management. ${ }^{2-8}$ Most of those studies included both transplant recipients with a functional renal allograft who did not require permanent dialysis and transplant recipients with a failing renal allograft who

From the Department of Cardiothoracic Surgery, ${ }^{\mathrm{a}}$ and Thomas E. Starzl Transplantation Institute, ${ }^{\mathrm{b}}$ University of Pittsburgh Medical Center, Pittsburgh, Pa.

Disclosures: Authors have nothing to disclose with regard to commercial support.

Received for publication March 15, 2012; revisions received Aug 27, 2012; accepted

for publication Oct 22, 2012; available ahead of print Nov 22, 2012.

Address for reprints: Christian A. Bermudez, MD, University of Pittsburgh Medical

Center-Presbyterian University Hospital, 200 Lothrop St, Suite C900, Pittsburgh,

PA 15213 (E-mail: bermudezc@upmc.edu).

$0022-5223 / \$ 36.00$

Copyright (c) 2014 by The American Association for Thoracic Surgery

http://dx.doi.org/10.1016/j.jtcvs.2012.10.037 required permanent dialysis at time of cardiac surgery. ${ }^{3,6}$ However, renal transplant recipients who undergo cardiac surgery and require permanent dialysis have different characteristics and outcomes than recipients who do not require dialysis. ${ }^{9}$ There are few reports analyzing shortand long-term outcomes of patients with a functioning renal allograft who undergo cardiac surgery. ${ }^{2,4}$ Moreover, a majority of the procedures described are coronary artery bypass grafting (CABG) or isolated valve surgeries; thus, the outcomes following other cardiac procedures, such as combined $\mathrm{CABG}$ and valve surgeries or aortic reconstructive procedures, remain unclear. The purpose of this study was to assess perioperative risk factors for mortality and long-term outcomes in renal transplant recipients with a functioning allograft who underwent cardiac surgery.

\section{PATIENTS AND METHODS Patients}

Data from our prospectively collected surgical database was retrospectively analyzed with the need for patient consent waived by the University of Pittsburgh Institutional Review Board. Mortality was confirmed using patient records and the Social Security Number Death Index. We identified 92 consecutive patients with a prior renal transplant and a functioning renal allograft who underwent cardiac surgery at the University of Pittsburgh Medical Center between July 1999 and April 2010. Five patients were also liver transplant recipients with functioning liver and kidney allografts 


\section{Abbreviations and Acronyms \\ $\mathrm{CABG}=$ coronary artery bypass grafting \\ $\mathrm{CPB}=$ cardiopulmonary bypass}

at the time of the cardiac procedure. The mean follow-up was $4.2 \pm 3.1$ years for discharged patients.

\section{Surgery}

All patients received a stress dose of steroids before anesthesia induction. Standard surgical techniques were used.

Cardiopulmonary bypass (CPB) flow was routinely maintained to provide a cardiac index of 2.2 to $2.4 \mathrm{~L} /$ minute $/ \mathrm{m}^{2}$ and a mean arterial pressure $>60$ $\mathrm{mm} \mathrm{Hg}$, using a roller pump and vasoconstrictors (ie, phenilephrine and norepinephrine), if required, during bypass. Hematocrit was maintained $>21 \%$, transfusing packed red blood cells per the surgeon's preference.

During the early operative period, per operative intensive care unit protocol, mean arterial pressure was maintained in a range from 60 to $70 \mathrm{~mm}$ $\mathrm{Hg}$ and central venous pressure was maintained from 12 to $15 \mathrm{~mm} \mathrm{Hg}$.

At first, colloids (albumin and hetastarch) were used to maintain adequate intravascular volume. Thereafter, mild to moderate vasoconstrictor doses were used selectively, as needed, avoiding their use in patients with severe preoperative renal dysfunction.

A target urine output of 0.5 to $1 \mathrm{~mL} / \mathrm{kg} /$ hour was intended during CPB. Diuretics (ie, furosemide) were used if persistent oliguria was noted.

When CABG was performed, the use of the off-pump versus on-pump technique was based on the surgeon's preference. When cardioplegia was required, intermittent doses of cold blood were administered in the standard fashion.

\section{Postoperative Care}

Standard perioperative management was used. Inotropes and vasoconstrictors were used intraoperatively and postoperatively, as needed, to stabilize hemodynamics. Special care was taken to maintain adequate renal perfusion pressure and to avoid all nephrotoxic drugs. Serum creatinine levels were closely monitored to assess renal function.

\section{Immunosuppressive Therapy}

All patients received their routine immunosuppressive medications until the evening before the cardiac surgery. Postoperatively, each patient's immunosuppression regimen was adjusted and closely monitored based on serum drug levels.

\section{Statistical Analysis}

Continuous variables are shown as means \pm standard deviation. Actuarial survival estimates were calculated using Kaplan-Meier life table analysis. Cox proportional-hazards regression was used to determine risk factors for 30-day survival, cardiac cause of death after discharge, and permanent renal failure requiring regular dialysis. Pre-, peri-, and postoperative variables with $P<.2$ from univariate analyses were retained for the multivariate regression tests. Statistical analysis was performed using SPSS version 18 (IBM Corp, Armonk, NY) software.

\section{RESULTS}

\section{Patient Demographics}

Preoperative characteristics of the 92 renal transplant recipients with a functioning allograft who underwent cardiac surgery are detailed in Table 1. All patients were following an immunosuppressive regimen. These included 76 patients receiving tacrolimus $(82 \%), 50$ patients receiving prednisone $(54 \%), 33$ patients receiving mycophenolate mofetil $(36 \%), 13$ patients receiving cyclosporine $(14 \%), 13$ patients receiving azathioprine $(14 \%)$, and 2 receiving sirolimus $(2 \%)$. Fifty-seven patients $(62 \%)$ were receiving prophylactic antibiotic therapy with oral sulfamethoxazole/trimethoprim at the time of their cardiac surgery.

\section{Operative and Postoperative Characteristics}

The interventions performed are outlined in Table 2. In this high risk cohort, 15 patients $(16 \%)$ were deemed to require urgent or emergent surgery. Mechanical support was required postcardiotomy in 7 patients $(8 \%)$, due to failure to wean from $\mathrm{CPB}$. An intra-aortic balloon pump was implemented immediately postoperatively in 6 patients $(6 \%)$, with 2 of these patients also requiring extracorporeal membrane oxygenation support with cannulation on the contralateral side from the renal allograft anastomosis. Intrahospital postoperative patient and allograft outcomes are presented in Table 3.

We subdivided our population into 5 groups (ie, CABG only, valve only, combined, aortic, and other). Mean CPB time and clamp time, respectively, were 107 minutes and 57 minutes for the CABG only group, 117 minutes and 90 minutes for the valve only group; 133 minutes and 97 minutes for the other procedures group, 173 minutes and 128 minutes for the combined group, and 200 minutes and 159 minutes for the aortic group ( $P=.01$ and .002 , respectively).

Glomerular filtration rates were not available after surgery. Mean intrahospital peak creatinine was $3.3 \pm 1.9$ $\mathrm{mg} / \mathrm{dL}$ and mean discharge creatinine was $2.2 \pm 1.3$ $\mathrm{mg} / \mathrm{dL}$ in patients not back to permanent dialysis on discharge. Compared with the mean preoperative creatinine $(2.1 \mathrm{mg} / \mathrm{dL})$, there was a mean creatinine elevation of 1.2 $\mathrm{mg} / \mathrm{dL}$ while in the hospital with near preoperative levels of creatinine at the time of discharge (mean elevation of $0.1 \mathrm{mg} / \mathrm{dL}$ compared with preoperative creatinine). Transient renal failure requiring dialysis occurred in 20 patients $(22 \%)$. Three of these patients did not recover renal function and required permanent dialysis.

\section{PATIENT SURVIVAL}

For the entire cohort, overall unadjusted survival was $88 \% 30$ days after cardiac surgery, $72 \%$ after 1 year, $47 \%$ after 5 years, and $30 \%$ after 8 years (Figure 1, $A$ ). Of the 11 patients who had a 30-day mortality, 3 patients underwent isolated CABG and their causes of death included cardiogenic shock, sepsis, and massive gastrointestinal bleeding. One patient died after mitral valve replacement surgery due to progressive heart failure. Four patients who underwent combined CABG and valve surgery died in the hospital from multiorgan failure (2 patients), sepsis, or cardiogenic shock. Two patients who underwent an aortic procedure did not survive for 30 days after surgery. Both 
TABLE 1. Patient demographics $(\mathbf{N}=92)$

\begin{tabular}{|c|c|}
\hline Characteristic & n $(\%)$ \\
\hline Mean age (y) & $57 \pm 11$ \\
\hline Female & $34(36)$ \\
\hline \multicolumn{2}{|l|}{ Comorbidities } \\
\hline Diabetes & $57(61)$ \\
\hline Insulin-dependent & $49(53)$ \\
\hline Hypertension & $81(88)$ \\
\hline Hyperlipidemia & $42(45)$ \\
\hline Smoking history & $30(32)$ \\
\hline CVA & $8(8)$ \\
\hline PVD & $55(59)$ \\
\hline COPD & $12(13)$ \\
\hline Mean preopoerative creatinine $(\mathrm{mg} / \mathrm{dL})$ & $2.1 \pm 1.2$ \\
\hline Mean preoperative GFR (mL/min) & $40 \pm 21$ \\
\hline Previous PCI & $15(16)$ \\
\hline Mean preoperative LVEF (\%) & $47 \pm 11$ \\
\hline$>45$ & $59(64)$ \\
\hline$<45->35$ & $21(23)$ \\
\hline$<35$ & $12(13)$ \\
\hline Emergency operation & $15(16)$ \\
\hline Recent AMI (<90 d) & $19(20)$ \\
\hline Pulmonary hypertension (systolic pressure $>60 \mathrm{~mm} \mathrm{Hg}$ ) & $22(24)$ \\
\hline Preoperative IABP & $3(3)$ \\
\hline Active endocarditis & $4(4)$ \\
\hline Mean duration of renal allograft (y) & $8.2 \pm 6.2$ \\
\hline \multicolumn{2}{|l|}{ Initial cause of renal transplantation } \\
\hline Diabetes & $29(31)$ \\
\hline Hypertension & $12(13)$ \\
\hline Nephritis & $31(34)$ \\
\hline Obstructive & $5(5)$ \\
\hline Polycystic kidney disease & $7(7)$ \\
\hline FK toxicity & $2(2)$ \\
\hline Other cause & $6(6)$ \\
\hline
\end{tabular}

$C V A$, Cerebrovascular accident; $P V D$, peripheral vascular disease; $C O P D$, chronic obstructive pulmonary disease; GFR, glomerular filtration rate; $P C I$, percutaneous cardiac intervention; $L V E F$, left ventricular ejection fraction; $A M I$, acute myocardial infarction; $I A B P$, intra-aortic balloon pump; $F K$, FK506 (tacrolimus).

presented to the hospital with type A aortic dissection, which was corrected surgically but progressed into cardiogenic shock. The other mortality within 30 days of cardiac surgery occurred after a combined CABG and maze procedure and was due to progressive heart failure.

Discharge was possible in 81 patients. At a mean followup of $4.2 \pm 3.1$ years, late mortality occurred in 46 of 81 patients $(56 \%)$. Fifteen patients had a cardiovascular cause of death after discharge, including acute myocardial infarction (7 patients), heart failure (4 patients), cerebrovascular accident ( 3 patients), and endocarditis (1 patient). Noncardiac causes of death after discharge included progressive renal failure (6 patients), sepsis (5 patients), head trauma ( 2 patients), and drug hepatotoxicity (1 patient). The other 17 patients died from unknown causes.

Among the 46 patients who died during follow-up, 13 of $46(28 \%)$ died under a dialysis regimen and 33 patients $(72 \%)$ died with a functioning allograft.
TABLE 2. Operative data $(\mathbf{N}=92)$

\begin{tabular}{lc}
\hline \multicolumn{1}{c}{ Operative characteristic } & $\mathbf{n}(\%)$ \\
\hline Type of surgery & \\
Isolated CABG & $43(46)$ \\
Off-pump & $22(23)$ \\
Isolated valve & $17(18)$ \\
AVR & $7(7)$ \\
MVR/repair & $7(7)$ \\
TVR & $2(2)$ \\
AVR + MVR & $1(1)$ \\
Combined CABG + valve & $18(19)$ \\
CABG + AVR & $9(10)$ \\
CABG + MVR/repair & $6(6)$ \\
CABG + AVR + MVR & $2(2)$ \\
CABG + AVR + MVR + TVR & $1(1)$ \\
Aortic reconstructive procedure & $7(7)$ \\
Ascending aortic repair/dissection & $4(4)$ \\
Ascending aortic repair/nondissection & $3(3)$ \\
Other & $7(7)$ \\
Septal myectomy + MVR & $3(3)$ \\
CABG + maze procedure & $2(2)$ \\
LV reconstruction & $1(1)$ \\
Removal of right atrial mass & $1(1)$ \\
Mean grafts used/CABG & $2.6 \pm 1.3$ \\
Arterial grafts & 57 \\
Bioprosthetic valve & $8(8)$ \\
Mechanical valve & $24(26)$ \\
Mean operative time (min) & $365 \pm 330$ \\
Mean cardiopulmonary bypass time (min) & $152 \pm 140$ \\
Mean aortic cross clamp time (min) & $110 \pm 105$ \\
IABP & $6(6)$ \\
ECMO & $3(3)$ \\
\hline vABG, Coronary artery bypass grafting; $A V R$, aortic valve replacement; \\
valve replacement; $T V R$, tricuspid valve repair; $L V$, left ventricle \\
balloon pump; $E C M O$, extracorporeal membrane oxygenation. \\
\end{tabular}

\section{Allograft Survival}

Three patients $(3 \%)$ with a functional allograft preoperatively were discharged with a permanent need for dialysis. One-year freedom from dialysis was $90 \%$. Mean creatinine was $2.8 \pm 2.0 \mathrm{mg} / \mathrm{dL} 1$ year after cardiac surgery. Five-year actuarial freedom from dialysis occurred in $66 \%$ and 8 -year freedom from dialysis in $49 \%$ (Figure $1, B$ ). At a mean follow-up of $4.2 \pm 3.1$ years, 3 of the 23 patients who eventually returned to permanent dialysis due to allograft failure received a second renal transplant. All of them were alive at the time of this report.

\section{Risk Factor Assessment}

Multivariate analysis of risk factors for 30-day mortality, death from a cardiac cause after discharge, and renal allograft failure requiring permanent dialysis after cardiac surgery are presented in Table 4. Risk factors for 30-day mortality after cardiac surgery were age $>65$ years, left ventricle ejection fraction $<35 \%$, and having undergone a combined $\mathrm{CABG}+$ valve procedure. Pulmonary 
TABLE 3. Postoperative patient and allograft outcomes $(\mathbf{N}=92)$

\begin{tabular}{|c|c|}
\hline Early postoperative characteristic & n $(\%)$ \\
\hline Extubation within $24 \mathrm{~h}$ & $59(64)$ \\
\hline Prolonged MV >3 d & $20(21)$ \\
\hline Reintubation & $9(10)$ \\
\hline Tracheostomy & $8(8)$ \\
\hline \multicolumn{2}{|l|}{ Infection } \\
\hline Superficial wound & $1(1)$ \\
\hline Leg wound & $2(2)$ \\
\hline Pneumonia & $7(7)$ \\
\hline Sepsis & $6(6)$ \\
\hline UTI & $2(2)$ \\
\hline Atrial fibrilation & $27(29)$ \\
\hline CVA & $6(6)$ \\
\hline Mean intrahospital peak creatinine (mg/dL) & $3.3 \pm 1.9$ \\
\hline Mean discharge creatinine (mg/dL) & $2.2 \pm 1.3$ \\
\hline Need for intrahospital dialysis & $20(22)$ \\
\hline Reoperation for bleeding & $3(3)$ \\
\hline AMI & $2(2)$ \\
\hline Ischemic bowel & $4(4)$ \\
\hline 30-d mortality & $11 / 92(12)$ \\
\hline \multicolumn{2}{|l|}{ 30-d mortality by procedure } \\
\hline CABG & $3 / 43(6)$ \\
\hline Valve & $1 / 17(5)$ \\
\hline $\mathrm{CABG}+$ valve & $4 / 18(22)$ \\
\hline Aortic procedure & $2 / 7(28)$ \\
\hline Other & $1 / 7(14)$ \\
\hline
\end{tabular}

$M V$, Mechanical ventilation; $U T I$, urinary tract infection; $C V A$, cerebrovascular accident; $A M I$, acute myocardial infarction; $C A B G$, coronary artery bypass grafting.

hypertension (defined as systolic pulmonary pressure $>60$ $\mathrm{mm} \mathrm{Hg}$ ) and diabetes as the primary cause for kidney transplantation were risk factors for death from a cardiac cause after discharge. Diabetes, dyslipidemia, preoperative use of an intra-aortic balloon pump, postoperative creatinine $>2 \mathrm{mg} / \mathrm{dL}$, and temporary need of dialysis perioperatively were associated with an increased risk for permanent allograft failure requiring dialysis after cardiac surgery.

\section{DISCUSSION}

With continued improvements in the medical management and long-term survival of renal transplant recipients, the need for eventual cardiac surgery in these high risk patients is increasing in frequency. It is clear that a cardiovascular impairment requiring invasive intervention shortens life expectancy of renal allograft recipients. According to the US Renal Data System 2010 annual data report, ${ }^{10}$ the 5 -year survival of kidney recipients ranges from $80 \%$ to $89 \%$. Nevertheless, the reported short- and long-term survival rates after cardiac surgery in renal transplant recipients are acceptable. Cardiovascular events are responsible for a majority of deaths in renal transplant recipients, ${ }^{11,12}$ and renal transplant recipients would experience significant morbidity and mortality if cardiac interventions were not performed.
In this study, we present an analysis of outcomes of patients with functioning renal allografts following a wide range of different cardiac surgery procedures. We found that surgery in these patients have acceptable outcomes, but that transient postoperative renal impairment, even if resolved at discharge, increases the risk for allograft failure during long-term follow-up. Because patients who had a combined CAGB and valve surgery are at increased risk for 30-day mortality, the renal transplant recipient's selection for surgery should be carefully considered if combined cardiac procedures are required.

The 30-day mortality of our cohort $(12 \%)$ was slightly higher than the range previously reported for renal transplant recipients who undergo cardiac surgery. For instance, Herzog and colleagues ${ }^{7}$ reported a 30 -day mortality of $5 \%$ to $9.4 \%$ for patients who underwent CABG after a renal transplant. In a recent single-center study, Ono and colleagues ${ }^{2}$ presented their experience with 46 kidney recipients who underwent cardiac surgery, reporting a 30-day mortality of $4.3 \%$, with isolated CABG surgery comprising $76 \%$ of the procedures and isolated valve surgeries comprising $20 \%$ of the procedures in the kidney recipients. John and colleagues ${ }^{3}$ reported a $1.4 \%$ mortality within 30 days after cardiac surgery, with isolated CABG comprising $93 \%$ of the performed interventions in their series of 70 patients. Our study differed from these studies; only $46 \%$ of patients underwent isolated CABG and 19\% underwent isolated valve procedures. Mortality occurred within 30 days of surgery in only $6 \%$ of patients who underwent isolated CABG, as presented in a previous study, ${ }^{13}$ which is consistent with previous reports. ${ }^{7}$ Furthermore, 18 cases $(19 \%)$ in our series were combined CABG and valve procedures, which was identified as a risk factor for 30-day mortality in our multivariable analysis. This is consistent with a previous study by Sharma and colleagues ${ }^{8}$ that suggested combined cardiac procedures may influence early mortality. In Sharma's series, this finding did not reach statistical significance, possibly due to the fact that the study compared combined $\mathrm{CABG}$ and valve surgery with isolated valve surgery, and isolated $\mathrm{CABG}$ was not included in the analysis. We also included 7 cases (7\%) of aortic procedures in our series, and these patients had a 30-day mortality of $28 \%$ ( 2 of 7 patients). Although aortic reconstructive procedures had high in-hospital mortality, this intervention was not identified as a multivariable risk factor for early death, likely limited by the small sample size of only 7 patients.

Long-term survival in renal transplant recipients who undergo valve replacement have noted a $52.8 \%$ overall survival in 5 years. ${ }^{8}$ In our cohort, survival was similar, with $47 \%$ surviving 5 years after cardiac surgery. Ono and colleagues ${ }^{2}$ reported a higher survival after the same follow-up period, with $67.9 \%$ of the patients alive. We believe that our results reflect the nature of our study population, with a higher number of cases of combined CABG 


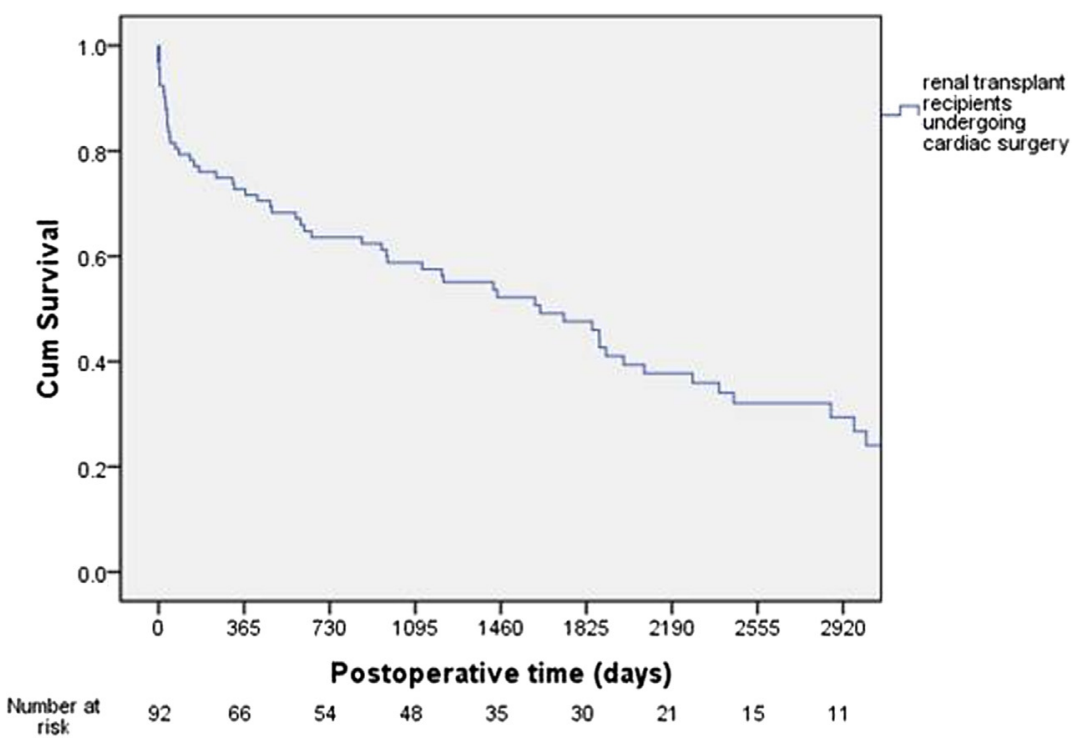

A

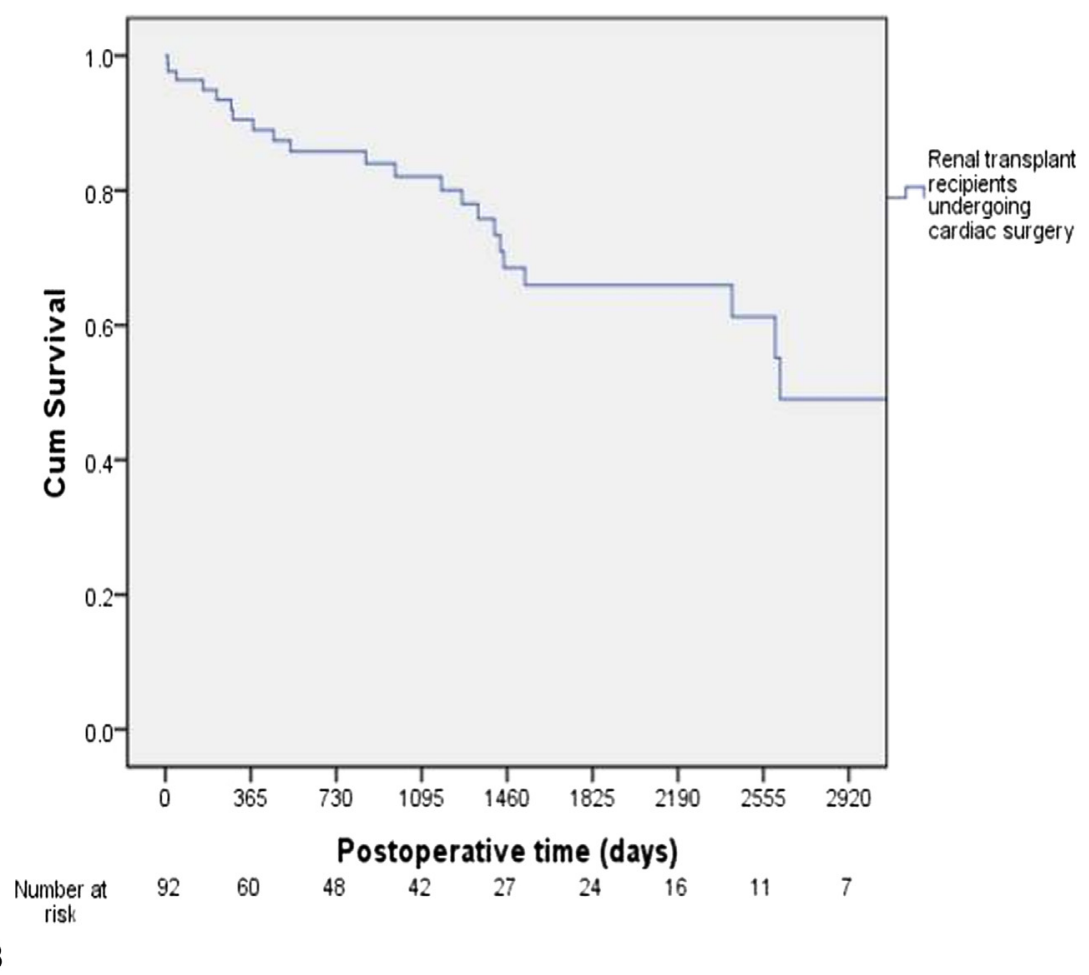

FIGURE 1. Survival and freedom from dialysis after cardiac surgery. A, Kaplan-Meier 8-year actuarial survival of renal transplant recipients who underwent cardiac surgery. B, Kaplan-Meier 8-year actuarial freedom from dialysis of renal transplant recipients who underwent cardiac surgery. Cum, Cumulative.

and valve surgery or aortic surgery carrying an increased morbi-mortality.

In our series, $22 \%$ of patients required dialysis perioperatively due to transient renal failure. In other studies of cardiac surgery in renal transplant recipients with functioning allograft, ${ }^{2,4}$ a lower rate of postoperative in-hospital dialysis was reported. Because the mean preoperative creatinine levels in our patients were similar to levels reported in those studies, we believe that the kidney may be significantly affected during the surgical procedure. The mean CPB and aortic cross clamp times were remarkably higher in our overall 92 cases when compared with other reports, and particularly in the 20 patients in whom intrahospital postoperative dialysis was required, with a mean cardiopulmonary bypass duration of $170 \pm 63$ minutes and mean aortic cross clamp time of $126 \pm 58$ minutes. However, only a small number of patients did not recover renal function and most were discharged without requiring a permanent 
TABLE 4. Multivariable Cox proportional hazards analysis for risk factors of 30-day mortality, cardiac cause of death, and permanent dialysis following complex cardiac surgery in patients with functioning renal allografts

\begin{tabular}{|c|c|c|c|}
\hline $\begin{array}{l}\text { Dependent } \\
\text { variables }\end{array}$ & Risk factor & HR $(95 \%$ CI $)$ & $\begin{array}{c}P \\
\text { value }\end{array}$ \\
\hline \multicolumn{4}{|l|}{ 30-d mortality } \\
\hline & Age $>65 y$ & $7.22(1.720-30.314)$ & .007 \\
\hline & $\mathrm{LVEF}<35 \%$ & $6.77(1.60-28.63)$ & .009 \\
\hline & CABG + Valve & $9.760(1.798-52.976)$ & .008 \\
\hline \multicolumn{4}{|c|}{$\begin{array}{l}\text { Death from a cardiac } \\
\text { cause after } \\
\text { discharge }\end{array}$} \\
\hline & PHTN & $3.26(1.086-9.790)$ & .035 \\
\hline & $\begin{array}{l}\text { Diabetes as cause } \\
\text { of kidney } \mathrm{Tx}\end{array}$ & $3.865(1.109-13.46)$ & .034 \\
\hline \multicolumn{4}{|c|}{$\begin{array}{l}\text { Permanent dialysis } \\
\text { required after } \\
\text { discharge }\end{array}$} \\
\hline & Diabetes & $4.731(1.521-14.718)$ & .007 \\
\hline & Dyslipidemia & 2.581 (1.077-6.185) & .033 \\
\hline & Preoperative IABP & $12.01(1.22-117.82)$ & .033 \\
\hline & $\begin{array}{l}\text { Postoperative } \\
\text { creatinine } \\
>2 \mathrm{mg} / \mathrm{dL}\end{array}$ & $8.082(1.553-42.05)$ & .013 \\
\hline & $\begin{array}{l}\text { Need for temporary } \\
\text { dialysis }\end{array}$ & $4.186(1.298-13.49)$ & .016 \\
\hline
\end{tabular}

$H R$, Hazard ratio; $C I$, confidence interval; $L V E F$, left ventricular ejection fraction; $C A B G$, coronary artery bypass grafting; $P H T N$, pulmonary hypertension; $T x$, transplant; $I A B P$, intra-aortic balloon pump.

dialysis regimen. Moreover, the mean discharge creatinine level was similar to the preoperative level $(2.2 \mathrm{mg} / \mathrm{dL}$ vs $2.1 \mathrm{mg} / \mathrm{dL}$, respectively).

Freedom from dialysis 5 and 8 years after cardiac surgery in our cohort was consistent to other reports. ${ }^{2}$ However, in our analysis, most risk factors associated with long-term permanent allograft failure were related to postoperative renal function parameters (need for temporary dialysis and postoperative creatinine $>2 \mathrm{mg} / \mathrm{dL}$ ) and primary preoperative renal allograft comorbidities (diabetes and dyslipidemia). These findings suggest that even with normalization of the creatinine values and allograft function at discharge in almost all cases, the transient renal impairment caused by the surgery may influence long-term allograft survival.

The limitations of the study are its retrospective nature and the relatively small number of patients included in our analysis. Nonetheless, to our knowledge, this series is currently the largest single-institution experience with complex cardiac surgery in patients with a functioning renal allograft. As such, the results from this report may provide guidance as to outcome trends, although a larger and perhaps multiinstitutional study to corroborate to our findings is needed.

\section{CONCLUSIONS}

Cardiac surgery in renal transplant recipients with a functioning allograft has acceptable outcomes. If combined cardiac procedures are required, the indications for surgical intervention should be carefully considered in this patient population. Patients with transient postoperative renal impairment, even if resolved at discharge, should be closely monitored during long-term follow-up for late allograft failure.

\section{References}

1. Krämer BK, Zülke C, Kammerl MC, Schmidt C, Hengstenberg C, Fischereder M, et al. Cardiovascular risk factors and estimated risk for CAD in a randomized trial comparing calcineurin inhibitors in renal transplantation. Am J Transplant. 2003;3:982-7.

2. Ono M, Wolf RK, Angouras DC, Brown DA, Goldstein AH, Michler RE. Shortand long-term results of open heart surgery in patients with abdominal solid organ transplant. Eur J Cardiothorac Surg. 2002;21:1061-72.

3. John R, Lietz K, Huddleston S, Matas A, Liao K, Shumway S, et al. Perioperative outcomes of cardiac surgery in kidney and kidney-pancreas transplant recipients. J Thorac Cardiovasc Surg. 2007;133:1212-9.

4. Zhang L, Garcia JM, Hill PC, Haile E, Light JA, Corso PJ. Cardiac surgery in renal transplant recipients: experience from Washington Hospital Center. Ann Thorac Surg. 2006;81:1379-84

5. Mitruka SN, Griffith BP, Kormos RL, Hattler BG, Pigula FA, Shapiro R, et al. Cardiac operations in solid-organ transplant recipients. Ann Thorac Surg. 1997;64:1270-8

6. Rahmanian PB, Adams DH, Castillo JG, Silvay G, Filsoufi F. Excellent results of cardiac surgery in patients with previous kidney transplantation. J Cardiothorac Vasc Anesth. 2009;23:8-13.

7. Herzog CA, Ma JZ, Collins AJ. Long-term outcome of renal transplant recipients in the United States after coronary revascularization procedures. Circulation. 2004;109:2866-71.

8. Sharma A, Gilbertson DT, Herzog CA. Survival of kidney transplantation patients in the United States after cardiac valve replacement. Circulation. 2010;121:2733-9.

9. Shroff GR, Li S, Herzog CA. Survival of patients on dialysis having off-pump versus on-pump coronary artery bypass surgery in the United States. $J$ Thorac Cardiovasc Surg. 2009;139:1333-8.

10. US Renal Data System. USRDS 2010 annual data report: atlas of chronic kidney disease \& end-stage renal disease in the United States. Bethesda, Md: National Institutes of Health, National Institute of Diabetes and Digestive and Kidney Diseases; 2010

11. Diethelm AG, Deierhoi MH, Hudson SL, Laskow DA, Julian BA, Gaston RS et al. Progress in renal transplantation. A single center study of 3359 patients over 25 years. Ann Surg. 1995;221:446-57.

12. de Mattos AM, Prather J, Olyaei AJ, Shibagaki Y, Keith DS, Mori M, et al. Cardiovascular events following renal transplantation: role of traditional and transplant-specific risk factors. Kidney Int. 2006;70:757-64.

13. Shayan H, Rocha R, Wei L, Gleason T, Zaldonis D, Pellegrini R, et al. Midterm outcomes of off-pump and on-pump coronary artery revascularization in renal transplant recipients. J Card Surg. 2011;26:591-5. 